\title{
Exogenous Nitric Oxide Negatively Impacts on Ethylene Emissions from Intact and Fresh-Cut Tomato Fruit
}

\author{
Mourad A.M. Aboul-Soud \\ Center of Excellence in Biotechnology Research, College of Science, \\ King Saud University, P.O. Box 2455, Riyadh 11451, Kingdom of Saudi Arabia
}

\begin{abstract}
The objective of this study was to investigate the effect of Nitric Oxide (NO) on the production of basal and wound-associated stress ethylene $\left(\mathrm{C}_{2} \mathrm{H}_{4}\right)$ from intact and fresh-cut tomato fruits, respectively. For this purpose, a non-invasive and online sampling technique based on Laser Photoacoustic Spectroscopy (LPAS) was employed. Pre-treatment of intact Mature Green (MG) tomato fruits with a low concentration (200 ppbv) of NO gas resulted in a significant and steady average reduction of $33 \%$ in the basal-level $\mathrm{C}_{2} \mathrm{H}_{4}$ production to $6.0 \pm 0.44 \mathrm{pmol} \mathrm{h}^{-1} \mathrm{~g} \mathrm{fwt}^{-1}$ compared to $9.0 \pm 0.18 \mathrm{pmol} \mathrm{h}^{-1} \mathrm{~g} \mathrm{fwt}^{-1}$ in the non-treated MG control. Moreover, $\mathrm{NO}$ gas fumigation of fresh-cut $\mathrm{MG}$ tomato fruit slices caused a $60 \%$ reduction in peak woundinduced $\mathrm{C}_{2} \mathrm{H}_{4}$ levels compared to untreated fresh-cut control fruit. These results clearly indicate that NO pre-treatment negatively impacts on both basal and wound-associated stress $\mathrm{C}_{2} \mathrm{H}_{4}$ emission levels, respectively in both intact and fresh-cut tomato fruits. These results are discussed in the light of possible mechanisms of $\mathrm{NO}$ interference with $\mathrm{C}_{2} \mathrm{H}_{4}$ biosynthesis. Moreover, the potential utilization of $\mathrm{NO}$ in controlling stress-induced and undesirable biochemical changes which are known to occur in fresh-cut fruits is highlighted.
\end{abstract}

Key words: Tomato, nitric oxide, ethylene biosynthesis, laser photoacoustic spectroscopy, fresh-cut fruits, Saudi Arabia

\section{INTRODUCTION}

Stress is generally defined as any environmental factor that is potentially unfavourable to living organisms (Levitt, 1972) with the exception of decay (i.e., biotic factors). Thus, quality losses in fresh-cut produce such as fruits and vegetables can be directly or indirectly attributable to a combination of abiotic stress and stressinduced senescence (Lester, 2003). In this context, wounding is one of the major stresses experienced by fresh-cut produce undergoing various forms of processing (e.g., slicing, dicing, chopping, trimming, peeling, coring and/or shredding). Internal and external factors that can affect the wound response include species, cultivar, maturity, storage/processing temperature, cutting protocols, $\mathrm{CO}_{2}$ and $\mathrm{O}_{2}$ levels and water vapour pressure (Brecht, 1995; Cantwell and Suslow, 2002). Increasing interest has recently been shown in prepacked/precut fresh fruit and vegetables because of the advantages offered by those commodities to consumers; e.g., convenience, freshness and low calorific content.

However, as a result of the active metabolism of the plant tissues caused by wounding damage and the exposure of cut surfaces to external factors, the produce changes from having a relative stability with a shelf-life of several weeks or months to a perishable product with a very short shelf-life (Lanciotti et al., 1999). During climacteric fruit ripening, the burst of autocatalytic ethylene $\left(\mathrm{C}_{2} \mathrm{H}_{4}\right)$ co-ordinates and accelerates the ripening process (Alexander and Grierson, 2002). Delaying fruit ripening by reducing $\mathrm{C}_{2} \mathrm{H}_{4}$ biosynthesis has been a major goal of postharvest physiologists for example via $\mathrm{C}_{2} \mathrm{H}_{4}$-suppressed transgenic plants (Hamilton et al., 1990; Oeller et al., 1991; Picton et al., 1993).

Ripening of fruits and senescence of flowers can also be controlled using 1-methyl cyclopropene (1-MCP) (Reid and Staby, 2008). However, the transgenic approach is time-consuming, financially-demanding and requires extensive studies and the use of 1-MCP may actually inhibit the occurrence of desirable changes in the produce that are induced by $\mathrm{C}_{2} \mathrm{H}_{4}$.

Fresh-cut processing and packaging protocols result in stress for fruit and vegetable tissues and much of this has been described as producing a shorter shelf-life for fresh-cut versus intact fruits and vegetables (MarÃa Gil et al., 2006). Fresh-cut fruits and vegetables exhibit increased respiration rates and wound-induced $\mathrm{C}_{2} \mathrm{H}_{4}$ production and increase the surface area per unit volume, thus exacerbating water loss (Toivonen and DeEll, 2002). Thus, development of non-hazardous and efficient procedures for preventing $\mathrm{C}_{2} \mathrm{H}_{4}$ accumulation or inhibiting $\mathrm{C}_{2} \mathrm{H}_{4}$ action on fresh-cut fruits would be of considerable commercial interest. 
For $>2$ decades, due to its diverse biological activities and general ubiquity, Nitric Oxide (NO) has been extensively studied in animal and plant research (Delledonne et al., 1998; Durner et al., 1998; Furchgott and Zawadzky, 1980; Ignarro et al., 1987; Koshland, 1992; Palmer et al., 1987; Wang et al., 2004; Aboul-Soud et al., 2009). NO is a bioactive molecule implicated in vegetative stress and senescence of horticultural products (Leshem and Haramaty, 1996).

Earlier, it has been reported that exogenous application of $\mathrm{NO}$, either by direct fumigation or via $\mathrm{NO}$ releasing chemicals, significantly extends shelf and postharvest lives of intact vegetables and climacteric and non-climacteric horticultural products (Leshem and Haramaty, 1996; Leshem and Wills, 1998; Leshem et al., 1998; Wills et al., 2000; Sozzi et al., 2003; Soegiarto and Wills, 2004; Zhu and Zhou, 2007; Zhu et al., 2006). Moreover, the emission of $\mathrm{NO}$ was negatively correlated with $\mathrm{C}_{2} \mathrm{H}_{4}$ output during the process of maturation and senescence of intact whole climacteric and non-climacteric fruits (Leshem and Pinchasov, 2000). However, detailed knowledge of the effects of NO treatment on freshly-cut fruits is seriously lacking. Hence, the objective of this study was to investigate the effect of exogenous $\mathrm{NO}$ on the production of stress $\mathrm{C}_{2} \mathrm{H}_{4}$ from intact and fresh-cut tomato fruits via a non-invasive detection using Laser Photoacoustic Spectroscopy (LPAS).

The obtained results are discussed in the light of possible mechanisms of $\mathrm{NO}$ interference with $\mathrm{C}_{2} \mathrm{H}_{4}$ biosynthesis. Moreover, the potential utilization of $\mathrm{NO}$ in controlling stress-induced and undesirable biochemical changes that are known to occur in fresh-cut fruits is highlighted.

\section{MATERIALS AND METHODS}

Plant growth: Experiments were performed using a near isogenic line of diploid Solanum lycopersicon Mill. cv. Ailsa Craig $\left(\mathrm{AC}^{++}\right)$plants that have been grown at Sutton Bonington, Leics., UK for over 20 years. All fruits utilised for experiments were grown in Sutton Bonington (Leic., UK) greenhouse facility in December 2003. Basically, plants were grown, maintained and flowers were tagged at anthesis as earlier described (Aboul-Soud and El-Shemy, 2009).

Fruits at Mature Green (MG) stage were detached from the plants with approximately $5 \mathrm{~cm}$ of pedicle and subsequently put in a well aerated box to avoid stressing the fruits. The fruits were air-shipped from Nottingham to Nijmegen, the Netherlands in a $<8 \mathrm{~h}$ duration from dispatch to arrival. Measurements were carried out within hours of arrival.
Fruit treatments: Tomato fruits were initially selected for uniformity of size and freedom from defects, infection and mechanical damage. Mature Green (MG) $\mathrm{AC}^{++}$fruits were all freshly cut for the wounding studies.

All samples were manually processed using disinfected stainless steel knives and plastic cutting boards. $\mathrm{MG} \mathrm{AC}^{++}$fruits were systematically cut in slices 10-12 mm thick. Subsequently, the resulting slices were then cut into 4 triangular pieces. For fruit treatment with $\mathrm{NO}$, a calibrated cylinder containing $\mathrm{NO}$ at a concentration of 1 ppm, purchased from NMI (National Metrological Institute, the Netherlands) was utilised. Thus, tomato fruits were fumigated overnight with NO gas at a physiological concentration of 200 part per billion volume (ppbv). This was accomplished by flushing fruit samples with a mixture of $\mathrm{NO}$ from the calibrated cylinder (NMI, the Netherlands) and ozone-free air at a total flow rate of $2 \mathrm{~L} \mathrm{~h}^{-1}$. In order to reach $200 \mathrm{ppbv} \mathrm{NO}$, a 5 time dilution of the $\mathrm{NO}$ from the calibrated cylinder was attained by mixing $0.4 \mathrm{~L} \mathrm{~h}^{-1} \mathrm{NO}$ flow with $1.6 \mathrm{~L} \mathrm{~h}^{-1}$ ozonefree air.

Real-time monitoring of $\mathrm{C}_{2} \mathrm{H}_{4}$ emission with LPAS: $\mathrm{C}_{2} \mathrm{H}_{4}$ production was monitored in real time via LPAS, employing a sensitive laser-based $\mathrm{C}_{2} \mathrm{H}_{4}$ detector in combination with a gas flow through system, essentially as described by Cristescu et al. (2002). A schematic diagram of the setup is shown in Fig. 1. Briefly, the system consists of a line-tunable $\mathrm{CO}_{2}$ laser that emits 9-11 $\mu \mathrm{m}$ infrared light into a Photoacoustic Absorption Cell (PAC) where $\mathrm{C}_{2} \mathrm{H}_{4}$ is detected.

The $\mathrm{C}_{2} \mathrm{H}_{4}$ gas mixtures are very sensitively measured by the laser-based $\mathrm{C}_{2} \mathrm{H}_{4}$ detector at tens of pptv levels (parts per trillion volume $=1: 10^{12}$ ) due to the distinct fingerprint-like spectrum of $\mathrm{C}_{2} \mathrm{H}_{4}$ in the $\mathrm{CO}_{2}$ laser wavelength range (Brewer et al., 1982). Tomato fruits are placed into closed glass cuvettes and continuously flushed with carrier gas at constant flow of $2 \mathrm{~L} \mathrm{~h}^{-1}$. A system of electric valves allowed three cuvettes with biological samples to be measured alternatively (Fig. 1a). Each cuvette was measured for about $15 \mathrm{~min}$. When not being measured, the gas flow through the cuvette was maintained but was vented into the (Fig. 1b). The obtained $\mathrm{C}_{2} \mathrm{H}_{4}$ levels corresponding to an empty cuvette were subtracted.

Ethylene emission from tomato fruits was related to the production rate by multiplying the measured value with the flow rate $\left(2 \mathrm{~L} \mathrm{~h}^{-1}\right)$ and divided by the fresh weight; the results were expressed in $\mathrm{pmol} \mathrm{h}^{-1}$ per $\mathrm{g}$ fresh weight (fwt). Each experiment was repeated at least three times, each of which produced essentially similar results. The data shown in Fig. 2 and 3 are of a typical experiment. 


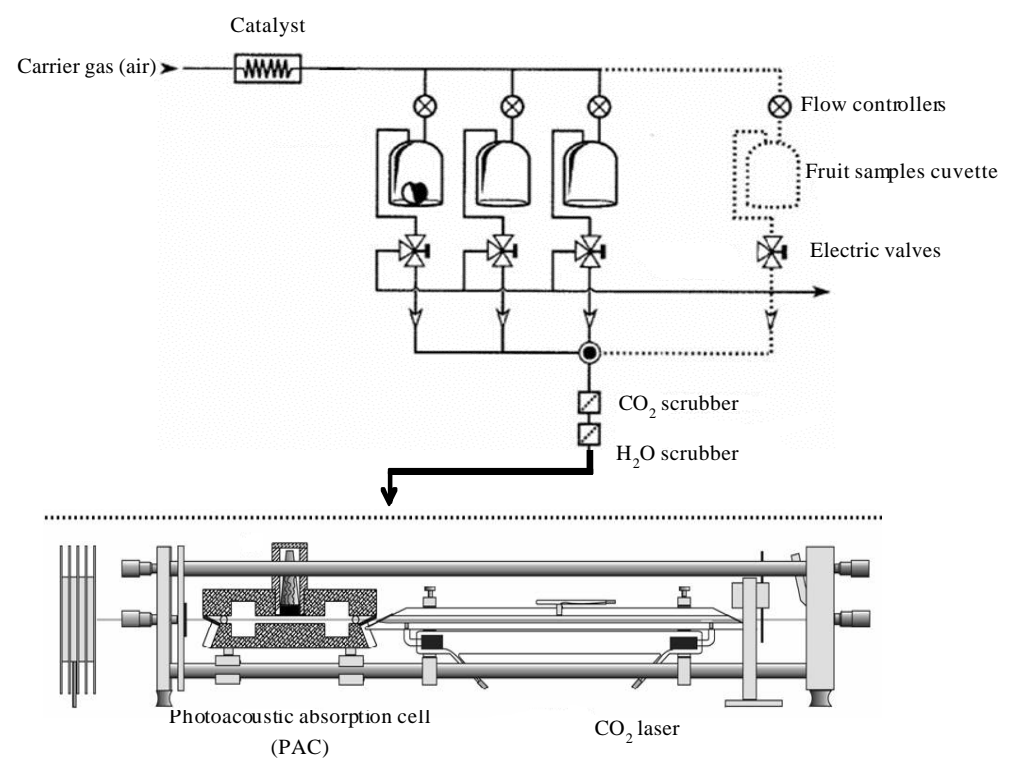

Fig. 1: Experimental setup for ethylene detection using LPAS; Gas sampling system. Compressed air is passed through a catalyst to obtain hydrocarbons-free air and used to flush the cuvettes containing the tomatoes at constant flow rate of $2.0 \mathrm{~L} \mathrm{~h}^{-1}$ (regulated by flow controllers). Each cuvette is connected alternatively to the measuring system by electric valves. Scrubbers with $\mathrm{KOH}$ and $\mathrm{CaCl}_{2}$ were placed before the PAC in order to reduce the $\mathrm{CO}_{2}$ and the water content in the gas flow; LPAS-based system. $\mathrm{A} \mathrm{CO}_{2}$ laser is used as laser source in combination with a photoacoustic absorption cell (PAC) for real-time measurement of $\mathrm{C}_{2} \mathrm{H}_{4}$

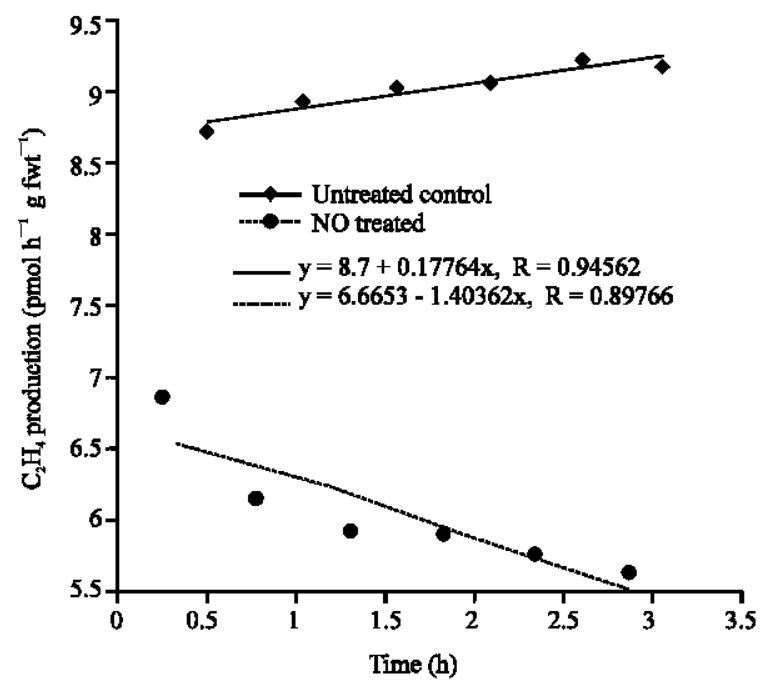

Fig. 2: Ethylene production in intact MG tomato fruits pre-treated with $\mathrm{NO}$ compared to untreated intact control, as detected using LPAS. NO-treated fruits were fumigated with $200 \mathrm{pbbv}$ according to materials and methods. Each sample cuvette was measured for approximately $15 \mathrm{~min}$. This figure shows averaged $\mathrm{C}_{2} \mathrm{H}_{4}$ emissions of typical data obtained over a $3 \mathrm{~h}$ monitoring period. The experiment was repeated twice with similar results

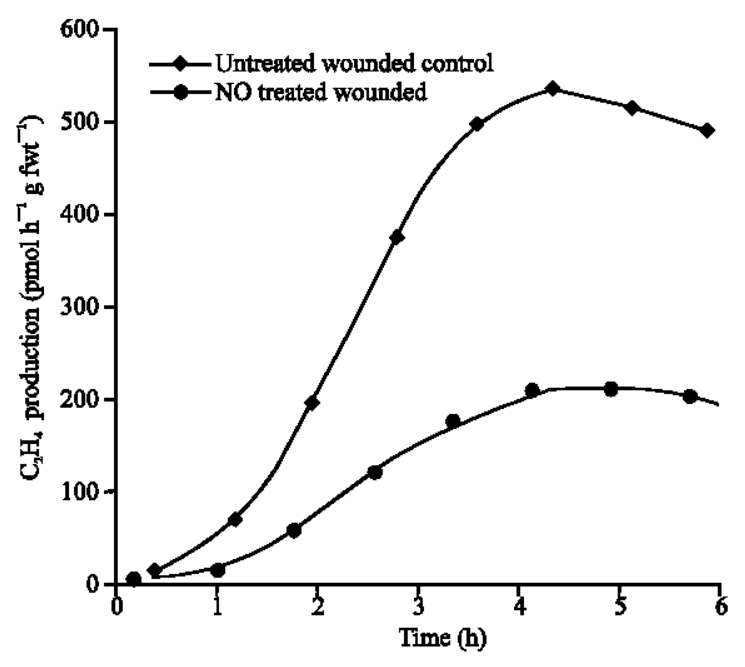

Fig. 3: Ethylene production by fresh-cut $\mathrm{MG}$ tomato fruits pre-treated with $\mathrm{NO}$ compared to untreated fresh-cut control, as detected using LPAS. NO-treated fruits were fumigated with 200 pbbv according to materials and methods. MG fruits were manually processed using disinfected stainless steel knives and were systematically cut in slices $10-12 \mathrm{~mm}$ thick. Subsequently, resulting slices were then cut into 4 triangular pieces 


\section{RESULTS AND DISCUSSION}

$\mathrm{NO}$ emissions were negatively linked to $\mathrm{C}_{2} \mathrm{H}_{4}$ production in intact climacteric and non-climacteric fruits (Leshem and Pinchasov, 2000). This raised the prospect that NO could have a role in the postharvest behaviour of horticultural produce, as exogenous $\mathrm{NO}$ fumigation has been shown to extend postharvest shelf-life and storage of intact fruits (Leshem and Wills, 1998; Leshem et al., 1998; Wills et al., 2000). However, a direct causal relationship between $\mathrm{NO}$ and $\mathrm{C}_{2} \mathrm{H}_{4}$ has not been investigated earlier, whether in intact or fresh-cut fruits. In this research, The researchers examined the direct effect of short-term application of $\mathrm{NO}$ gas, at low concentration on levels of $\mathrm{C}_{2} \mathrm{H}_{4}$ production in tomato fruit. For this purpose, a direct-trace gas, non-invasive and online sampling technique based on LPAS was employed. Thus, $\mathrm{C}_{2} \mathrm{H}_{4}$ emissions from MG fruits which had been pretreated with NO gas at a concentration of $200 \mathrm{ppbv}$ were monitored in real-time via LPAS. Ethylene production from intact tomato fruits at three different developmental stages (namely: Mature Green $(\mathrm{MG})$, Breaker $(\mathrm{B})$ and $\mathrm{B}+5$ ) was monitored.

Typically, $\mathrm{C}_{2} \mathrm{H}_{4}$ levels of $16.93 \pm 2.72,151.01 \pm 18.33$ and $718.19 \pm 42.16 \mathrm{pmol} \mathrm{h}^{-1} \mathrm{~g}_{\text {fwt }}{ }^{-1}$ were produced by MG, B and $\mathrm{B}+5$ fruits, respectively over $13 \mathrm{~h}$ period. These values fall within the expected normal $\mathrm{C}_{2} \mathrm{H}_{4}$ evolution range for each respective developmental stage. Strikingly, pre-treatment of intact MG tomato fruits with $200 \mathrm{pbbv}$ $\mathrm{NO}$ gas resulted in a significant steady reduction in $\mathrm{C}_{2} \mathrm{H}_{4}$ production level (Fig. 2). Specifically, an overall average reduction of $33.33 \%$ in $\mathrm{C}_{2} \mathrm{H}_{4}$ production level was observed when intact $\mathrm{MG}$ tomato fruits were fumigated with $\mathrm{NO}$ gas $\left(6.0 \pm 0.44 \mathrm{pmol} \mathrm{h}^{-1} \mathrm{~g} \mathrm{fwt}^{-1}\right)$, as compared to non-treated MG control $\left(9.0 \pm 0.18 \mathrm{pmol} \mathrm{h}^{-1} \mathrm{~g} \mathrm{fwt}^{-1}\right)$ (Fig. 2). It is noteworthy that the reduction in $\mathrm{C}_{2} \mathrm{H}_{4}$ emission becomes greater the longer the experiment continues being 6.61 and $5.63 \mathrm{pmol} \mathrm{h}^{-1} \mathrm{~g} \mathrm{fwt}^{-1}$ at 0.77 and $2.86 \mathrm{~h}$, respectively (Fig. 2 ).

In addition, to test the effect of $\mathrm{NO}$ on wound induced $\mathrm{C}_{2} \mathrm{H}_{4}$ levels, fresh-cut $\mathrm{MG}$ tomato fruits were employed. Interestingly, $\mathrm{NO}$ gas fumigation caused approximately $60 \%$ reduction in peak $\mathrm{C}_{2} \mathrm{H}_{4}$ levels in freshcut $\mathrm{MG}$ tomato fruits as compared to untreated fresh-cut control (Fig. 3). Taken together, these results clearly indicate that $\mathrm{NO}$ pre-treatment negatively impacts on $\mathrm{C}_{2} \mathrm{H}_{4}$ production levels in both intact and fresh-cut tomato fruits. A possible explanation of this observed phenomenon is that NO negatively interferes with the enzymatic activity of one or more key enzymes in the $\mathrm{C}_{2} \mathrm{H}_{4}$ biosynthetic pathway, thereby influencing maturation and senescence of plant tissue. Hence, it is suggested that both gases act antagonistically.
The chemical nature of $\mathrm{NO}$ results in transition metals (e.g., $\mathrm{Fe}, \mathrm{Cu}, \mathrm{Zn}$ ) and proteins containing thiol groups being important targets for this molecule (Wendehenne et al., 2001). Thus, it has earlier reported that NO inhibits the activity of aconitase ( $\mathrm{Fe}-\mathrm{S}$ ) and haemcontaining enzymes (e.g., Catalase and peroxidase) resulting in the modulation of reactive oxygen species generation and detoxification (Clarke et al., 2000; Ferrer and Barcelo, 1999). In strawberry, a non-climacteric fruit, with low $\mathrm{C}_{2} \mathrm{H}_{4}$ production rate after harvest, it has been reported that $\mathrm{NO}$ could decrease $\mathrm{C}_{2} \mathrm{H}_{4}$ production through inhibition of 1-Aminocyclopropane-1-Carboxylic acid (ACC) synthase activity but not ACC oxidase; thus, reducing $\mathrm{ACC}$ content ( $\mathrm{Zhu}$ and Zhou, 2007). Thus, NO treatment was hypothesized to have no effect on the conversion of ACC to ethylene; it only prevented ACC synthesis through ACS deactivation (Zhu and Zhou, 2007). Moreover, another report showed that NO directly acts by down-regulating $\mathrm{C}_{2} \mathrm{H}_{4}$ synthesis through $\mathrm{S}$ nitrosylation of Methionine Adenosyltransferase (MAT1) in Arabidopsis plants (Lindermayr et al., 2006).

The attachment of $\mathrm{NO}$ leads to the inhibition of MAT1 activity and results in the reduction of the pool of the $\mathrm{C}_{2} \mathrm{H}_{4}$ precursor $\mathrm{S}$-Adenosylmethionine (SAM) (Lindermayr et al., 2006). In this research, it was shown for the first time that exogenous NO negatively modulates $\mathrm{C}_{2} \mathrm{H}_{4}$ production in fresh-cut $\mathrm{MG}$ tomato fruits (Fig. 3).

In this context, it has been previously reported that NO donors strongly inhibit the gene expression of wound signalling-associated genes (e.g., proteinase inhibitor) in young excised tomato plants (Orozco-Cardenas and Ryan, 2002). Hence, it is possible that NO can potentially be used in controlling stress-induced and undesirable biochemical changes that are known to occur in fresh-cut tissues, including fruits. Taken together, the key to achieving improved shelf-life, quality and nutritional status in fresh-cut products is to understand the mechanism of wound-induced change in the tissue physiology and metabolism. Once the mechanism of the wound-induced change is understood, then approaches to delay, inhibit or ameliorate the stress can be reliably developed.

Further studies are needed to determine the protective effect of NO on fruit nutritional value, quality parameters and on the synthesis of undesirable compounds with toxic or allergenic properties.

\section{ACKNOWLEDGEMENTS}

This research was supported by the European Union (EU) EU-FP6-Infrastructures-5 program, project FP6-026183 'Life Science Trace Gas Facility'. Thanks are due to Lucas Laarhoven and Simona Cristescu for the technical training with LPAS, set-up and data collection. 


\section{REFERENCES}

Aboul-Soud, M.A.M., M.M. Aboul-Enein and G.J. Loake, 2009. Nitric oxide triggers specific and dosedependent cytosolic calcium transients in Arabidopsis. Plant Signal Behav., 4: 191-196.

Aboul-Soud, M.A.M. and H.A. El-Shemy, 2009. Identification and subcellular localisation of S1;INT7: A novel tomato (Solanum lycopersicum Mill.) fruit ripening-related and stress-inducible gene. Plant Sci., 176: $241-247$.

Alexander, L. and D. Grierson, 2002. Ethylene biosynthesis and action in tomato: A model for climacteric fruit ripening. J. Exp. Bot., 53: 2039-2055.

Brecht, J.K., 1995. Physiology of lightly processed fruits and vegetables. Hort. Sci., 30: 18-22.

Brewer, R.J., C.W. Bruce and J.L. Mater, 1982. Optoacoustic spectroscopy of $\mathrm{C}_{2} \mathrm{H}_{4}$. Appl. Opt., 21: 4092-4100.

Cantwell, M. and T. Suslow, 2002. Postharvest Handling Systems: Minimally Processed Fruits and Vegetables. In: Postharvest Technology of Horticultural Crops, 3rd Edn., Kader, A.A. (Ed.). Univ. California Special Publ., California, pp: 445-463.

Clarke, A., R. Desikan, R.D. Hurst, J.T. Hancock and S.T. Neill, 2000. No way back: Nitric oxide and programmed cell death in Arabidopsis thaliana suspension cultures. Plant J., 4: 667-677.

Cristescu, S.M., D. de Martinis, T. Lintel, S. Hekkert, D.H. Parker and F.J.M. Harren, 2002. Ethylene production by Botrytis cinerea in vitro and in tomatoes. Applied Environ. Microbiol., 68: 5342-5350.

Delledonne, M., Y.J. Xia, R.A. Dixon and C. Lamb, 1998. Nitric oxide functions as a signal in plant disease resistance. Nature, 394: 585-588.

Durner, J., D. Wendehenne and D.F. Klessig, 1998. Defense gene induction in tobacco by nitric oxide, cyclic GMP and cyclic ADP-ribose. Proc. Natl. Acad. Sci. USA., 95: 10328-10333.

Ferrer, M.A. and A.R. Barcelo, 1999. Differential effects of nitric oxide on peroxidase and $\mathrm{H}_{2} \mathrm{O}_{2}$ production by the xylem of Zinnia elegans. Plant Cell Environ., 22: 891-897.

Furchgott, R.F. and J.V. Zawadzky, 1980. The obligatory role of endothelial cells in the relaxation of arterial smooth muscle by acetylcholine. Nature, 288: 373-376.

Hamilton, G., W. Lycett and D. Grierson, 1990. Antisense gene that inhibits synthesis of the hormone ethlene in transgenic plants. Nature, 364: 284-287.

Ignarro, L.J., G.M. Buga, K.S. Wood, R.E. Byrns and G. Chaudhuri, 1987. Endothelium-derived relaxing factor produced and released from artery and vein is nitric oxide. Proc. Natl. Acad. Sci. USA., 84: 9265-9269.
Koshland, D.E., 1992. The molecule of the year. Science, 258: $1861-1861$.

Lanciotti, R., M.R. Corbo, F. Gardini, M. Sinigaglia and M.E. Guerzoni, 1999. Effect of hexanal on shelf life of fresh apple slices. J. Agric. Food Chem., 47: 4769-4776.

Leshem, Y.Y. and E. Haramaty, 1996. The characterization and contrasting effects of the nitric oxide free radical in vegetative stress and senescence of Pisum sativum Linn foliage. J. Plant Physiol., 148: 258-263.

Leshem, Y.Y. and R.B.H. Wills, 1998. Harnessing senescence delaying gases nitric oxide and nitrous oxide, a novel approach to postharvest control of fresh horticultural produce. Biol. Plantarum, 41: 1-10.

Leshem, Y.Y. and Y. Pinchasov, 2000. Non-invasive photoacoustic spectroscopic determination of relative endogenous nitric oxide and ethylene content stoichiometry during the fruit ripening of strawberries Fragaria anannasa (Duch.) and avocados Persea Americana (Mill.). J. Exp. Bot., 349: 1471-1473.

Leshem, Y.Y., R.B.H. Wills and V.V.V. Ku, 1998. Evidence for the function of free radical gas-nitric oxide (NO)as an endogenous maturation and senescence regulation factor in higher plants. Plant Physiol. Biochem., 36: 825-833.

Lester, G.E., 2003. Oxidative Stress Affecting Fruit Senescence. In: Postharvest Oxidative Stress in Horticultural Crops, Hodges, D.M. (Ed.). The Haworth Press Inc., Binghamton, New York, pp: 113-129.

Levitt, J., 1972. Responses of Plants to Environmental Stresses. Academic Press, New York, pp: 697.

Lindermayr, C, G. Saalbach, G. Bahnweg and J. Durner, 2006. Differential inhibition of Arabidopsis methionine adenosyltransferases by protein Snitrosylation. J. Biol. Chem., 381: 4285-4291.

MarÃa Gil, I., A. Encarna and A. Adel Kader, 2006. Quality changes and nutrient retention in fresh-cut versus whole fruits during storage. J. Agric. Food Chem., 54: 4284-4296.

Oeller, P.W., L.M. Wong, L.P. Taylor, D.A. Pike and A. Theologis, 1991. Reversible inhibition of tomato fruit senescence by antisense RNA. Sci., 254: 437-439.

Orozco-Cardenas, M.L. and C.A. Ryan, 2002. Nitric Oxide negatively modulates wound signaling in tomato plants. Plant Physiol. 130: 487-493.

Palmer, R.M., A.G. Ferrige and S. Moncada, 1987. Nitric oxide release accounts for the biological activity of endothelium-derived relaxing factor. Nature, 327: 524-526.

Picton, S., S.L. Barton, M. Bouzayen, A.J. Hamilton and D. Grierson, 1993. Altered fruit ripening and leaf senescence in tomatoes expressing an antisense ethylene-forming enzyme transgene. Plant J., 3: 469-481. 
Reid, M.S. and G.L. Staby, 2008. A brief history of 1methycyclopropene. Hort Sci., 43: 83-85.

Soegiarto, L. andR.B.H. Wills, 2004. Short term fumigation with nitric oxide gas in air to extend the postharvest life of broccoli, green bean and bok choy. Hort Technol., 14: 538-540.

Sozzi, G.O., G.D. Trinchero and A.A. Fraschina, 2003. Delayed ripening of Bartlett pears treated with nitric oxide. J. Hort Sci. Biotechnol., 78: 899-903.

Toivonen, P.M.A. and J.R. DeEll, 2002. Physiology of Fresh-Cut Fruits and Vegetables. In: Physiology of Fresh-Cut Fruits and Vegetables: Science, Technology and Market, Lamikanra, O. (Ed.). CRC Press, Boca Raton, FL., pp: 91-123.

Wang, X., J.E. Tanus-Santos, C.D. Reiter, A. Dejam and S. Shivaet al, 2004. Biological activity of nitric oxide in the plasmatic compartment. Proc. Natl. Acad. Sci., 101: 11477-14482.
Wendehenne, D., A. Pugin, D. Klessig and J. Durner, 2001. Nitric oxide: Comparative synthesis and signaling in animal and plant cells. Trends Plant Sci., 6: 177-183.

Wills, R.B.H., V.V.V. Ku and Y.Y. Leshem, 2000. Fumigation with nitric oxide to extend the postharvest life of strawberries. Postharvest Biol. Technol., 18: 75-79.

Zhu, S. and J. Zhou, 2007. Effect of nitric oxide on ethylene production in strawberry fruit during storage. Food Chem., 100: 1517-1522.

Zhu, S., M. Liu and J. Zhou, 2006. Inhibition by nitric oxide of ethylene biosynthesis and lipoxygenase activity in peach fruit during storage. Postharvest Biol. Technol., 42: 41-48. 